\title{
Pembentukan Karakter Religius Pada Anak Usia Dini (Studi Pada RA Al Wafa Desa Ambulu Kec. Sumberasih Kab. Probolinggo)
}

\author{
1M. Syahid Syafa'at, ${ }^{2 *}$ Benny Prasetiya, ${ }^{3}$ Ulil Hidayah \\ Sekolah Tinggi Agama Islam Muhammadiyah Probolinggo \\ E-mail: *prasetiyabenny@gmail.com
}

\begin{abstract}
Abstrak: Karakter religius adalah salah satu sifat yang harus dimiliki semua manusia. Pembentukan karakter religius tidak dapat terbentuk dengan sendirinya. Maka dari itu, pendidikan karakter harus dibentuk sedini mungkin agar pembentukannya cukup mudah. Karakter religius ini dapat diperoleh dengan adanya kemauan dorongan dari lingkungan sekitar termasuk guru atau pendidik termasuk keluarga. Keluarga memiliki peran yang sangat penting dalam pementukan karakter anak usia dini. Begitu juga dengan lingkungan disekitar, harus bisa memberikan contoh yang baik, harus bisa memberikan suri tauladan yang baik yang berkaitan dengan pendidikan karakter religius setiap hari. Sehingga peserta didik bisa melihat, mengamati dan mencontoh terhadap perilaku yang bertujuan membentuk sebuah karakter religius. Dengan demikian, pendidikan tidak harus dilakukan didalam kelas melainkan juga bisa dilakukan diluar kelas. Pola pikir anak usia dini masih sangat bagus, daya ingat dan perilaku mencontoh terhadap apa yang dilihatnya adalah kelebihan bagi anak usia dini. Anak usai dini lebih sering mencontoh apa yang dilakukan dari pada apa yang dikatakan. Dalam hal ini, peneliti akan mencari tahu bagaimana proses pendidikan karakter yang dilakukan di RA Al-Wafa. Tujuan dari penelitian ini adalah, mengetahui proses pembelajaran pendidikan karakter di RA Al-Wafa dan mengetahui strategi yang digunakan. Peneliti menggunakan metode kualitatif dengan jenis penelitian studi kasus dengan melakukan wawancara terhadap pendidik atau guru di RA Al-Wafa terkait proses dan strategi yang digunakan.
\end{abstract}

Kata kunci: Karakter Religious, Pendidikan Karakter, Peserta Didik, Anak Usia Dini.

Abstract: Religious character is one of the qualities that all human beings must possess. The formation of religious character cannot be formed by itself. Therefore, character education must be formed as early as possible so that its formation is quite easy. This religious character can be obtained with the willingness of encouragement from the surrounding environment including teachers or educators including family. The family has a very important role in determining the character of early childhood. Likewise with the surrounding environment, must be able to provide a good example, must be able to provide good role models related to religious character education every day. So that students can see, observe and imitate behavior that aims to form a religious character. Thus, education does not have to be done in the classroom but can also be done outside the classroom. The mindset of early childhood is still very good, the memory and behavior of imitating what they see are advantages for early childhood. Early childhood often imitates what is done rather than what is said. In this case, the researcher will find out how the character education process is carried out at RA Al-Wafa. The purpose of this research is to know the learning process of character education in RA Al-Wafa and to know the strategies used. The researcher uses a qualitative method with the type of case study research by conducting interviews with educators or teachers at RA Al-Wafa regarding the processes and strategies used.

Keywords: Religious Character, Character Education, Students, Early Childhood. 


\section{PENDAHULUAN}

Perkembangan negara indonesia pada masa ini sangatlah pesat bahkan sudah modern. Teknologi bisa ditemukan diberbagai tempat tanpa harus susah payah untuk menemukannya. Handphone, laptop dan alat komunikasi lainnya sudah banyak dijual diluar sana. Akses internet pun sudah menjadi hal yang sangat mudah dijangkau.

Menghadapi tantangan di era industri 4.0 ini, penguatan pendidikan karakter adalah suatu yang harus dilaksanakan secara maksimal. Pasalnya, peluang dan tantangan pada era revolusi industri 4.0 ini berbeda dengan periode-periode sebelumnya. Di era industri 4.0 ini, penggunaan internet secara masif telah menjadi sebuah kebutuhan diberbagai kalangan termasuk dalam bidang pendidikan. Generasi baru di indonesia pada era 4.0 ini, mempunyai tantangan baru, bahkan pengetahuan teroi saja belum cukup unntuk membekali mereka untuk bertahan di era teknologi yang canggih dan pintar ini. Kebebasan masyarakan untuk mengakses informasi memungkinkan dapat mempengaruhi bahkan mengubah karakter mereka, baik bagaimana mereka berfikir maupun ber perilaku ${ }^{1}$.

Pendidikan karakter pada masa ini kurang begitu diperioritaskan sehingga terjadilah pemrosotan karakter yang sangat luar biasa. Demi menjaga dan menguatkan karakter anak bangsa, sebagai guru atau pengajar harus bisa memberikan bekal yang kuat untuk anak didiknya utamanya pada pendidikan usia dini.

Menurut 2 pengajar atau guru yang baik dan profesional, harus bisa menunjukkan keahliannya dalam proses pembelajaran dikelas maupun diluar kelas untuk mendapatkan hasil yang maksimal. Untuk menciptakan proses pembelajaran yang efisien, seorang guru atau pengajar harus betul-betul memahami strategi yang akan digunakan dalam menyampaikan pelajarannya.

Begitu banyak pemuda sekarang yang bertingkah semaunya tanpa memperdulikan lingkungan sekitar. Dan tanpa mereka sadari dari tingkahnya merugikan lingkungan dan merugikan orang lain. Namun, tidak ada sedikitpun rasa tanggung jawab yang muncul pada perilaku tersebut. Keluarga adalah permulaan dalam pendidikan seorang anak. Orang tua harus mengontrol setiap pertumbuhan pada seorang anak mulai sejak dini, baik dari sikap maupun tingkah laku, agar pertumbuhan anak bisa maksimal ${ }^{3}$.

Pendidika karakter adalah pendidikan yang membutuhkan pengaplikasian dalam semua lingkungan, dalam keluarga maupun disekolah. Pendidikan karakter

1 Dinno (STKIP Siliwangi Bandung) Mulyono, "Menegaskan Karakter Pendidikan Nonformal," Jurnal Ilmiah Program Studi Pendidikan Luar Sekolah STKIP Siliwangi Bandung 1, no. 1 (2012): 63-68, http://e-journal.stkipsiliwangi.ac.id/index.php/empowerment/article/view/365.

${ }^{2}$ Anitah (2007)

3 Mufatihatut Taubah, "PENDIDIKAN ANAK DALAM KELUARGA PERSPEKTIF ISLAM Mufatihatut Taubah (Dosen STAIN Kudus Prodi PAI)," JUrnal Pendidikan Agama Islam 3, no. 1 (2016): 109-36, http://jurnalpai.uinsby.ac.id/index.php/jurnalpai/article/view/41. 
tidak perlu catatan ataupun hafalan yang harus dilakukan oleh anak didik yang mana hal tersebut memerlukan evaluasi yang berkesinambungan ${ }^{4}$. Sehingga dengan ditanamkannya pendidikan karakter pada anak didik, peserta didik diharapkan dapan mengenal jati dirinya dan dapat mengetahui nilai-nilai ketuhanan ${ }^{5}$.

Dari beberapa pendapat diatas, pendidikan karakter yang baik bagi generasi bangsa ini sangat diperlukan bahkan harus betul-betul diperioritaskan. Maka dari itu, pengangkatan judul ini sangat penting untuk kita bahas agar pendidik dapat betulbetul mengedepankan pendidikan karakter mulai tingkat anak usia dini (AUD). Khususnya bagi warga kabupaten probolinggo, pendidikan karakter yang baik bagi generasi kita harus lebih di tingkatkan lagi sehingga generasi penerus bangsa kita bisa menghadapi tantangan-tantangan di era revolusi industri 4.0 ini.

Maka dari itu, bukan cuma di kalangan pendidikan yang harus menerapkan pembentukan karakter, tapi dikalangan masyarakat luar lebih-lebih dalam keluarga harus ikut andil dalam membetuk karakter generasi penerus bangsa ini agar mendapatkan hasil yang maksimal.

\section{METODE PENELITIAN}

Jenis penelitian yang dilakukan oleh penulis adalah penelitian dalam bentuk kualitatif. Metode kualitatif adalah suatu metode yang digunakan dalam membuat sebuah karya yang mana isi dan pembahasannya membutuhkan banyak referensireferensi dari buku jurnal dan yang lainnya. Sehingga memudahkan penulis untuk menemukan jawaban-jawaban atau bahan yang akan dicantumkan dalam tulisannya ${ }^{6}$. Dalam penelitian kali ini, peneliti menggunakan beberapa referensi untuk menyempurnakan pembahasan yang ada dalam penelitiannya, beserta melakukan wawancara untuk menambah wawasan yang ada dalam penelitian.

\section{PEMBAHASAN}

\section{Strategi Pendidikan Karakter Religius Bagi Anak Usia dini di RA Al Wafa}

Bagian ini merupakan bagian utama artikel hasil penelitian dan biasanya merupakan bagian terpanjang dari suatu artikel. Hasil penelitian yang disajikan dalam bagian ini adalah hasil "bersih". Proses analisis data seperti perhitungan statistik dan proses pengujian hipotesis tidak perlu disajikan. Hanya hasil analisis dan hasil pengujian hipotesis saja yang perlu dilaporkan. Tabel dan grafik dapat digunakan untuk memperjelas penyajian hasil penelitian secara verbal. Tabel dan grafik harus diberi komentar atau dibahas.

\footnotetext{
${ }^{4}$ Prasetiya 2021)

${ }^{5}$ Prasetiya, Rofi, and Setiawan 2018)

${ }^{6}$ M.Pd Dr. Wahidmurni, "PEMAPARAN METODE PENELITIAN KUALITATIF," Reserach Repository 549, no. 1 (2017): 40-42.
} 
Ra Al Wafa adalah kembaga pendidikan yang berada di bawah naungan yayasan pondok pesantren yang bertempat di desa ambulu kecamatan sumberasih kabupaten probolinggo. Pondok pesantren tersebut diasuh langsung oleh keturunan Rasulallah. Yayasan Pondok Pesantren Darul Akhlaq As-Syafi'iyah adalah nama dari yayasan tersebut. Lembaga yang ada dinaungan yayasan pondok pesantren darul akhlaq diantaranya Pondok Pesantren Darul Akhlaq, RA, Al Wafa, SMP Darul Akhlaq dan SMA Darul Akhlaq. RA Al Wafa berdiri pada tahun 2010 yang mana dipimpin langsung oleh pengasuh Pondok Pesantren Darul Akhlaq Syarifah Muaffah Binti Husain As Segaf. Melihat dari lembanag RA yang berada dalam naungan yayasan pondok pesantren, pendidikan karakter religius tentunya menjadi salah satu pendidikan yang diperioritaskan.

Pada masa Orde Baru, pembangunan karakter bangsa Indonesia adalah menjadi prioritas utama pendidikan nasional. Pemerintah Orde Baru memberikan porsi yang signifikan bagi pengembangan karakter siswa, terutama melalui beberapa pelajaran seperti Pendidikan Moral Pancasila (PMP), Pendidikan Pancasila dan Kewarganegaraan (CIVICS). Sayangnya, sifat ideologis pendidikan karakter saat itu sangat dominan, sehingga substansi karakter yang dikembangkan lebih berorientasi pada pembangunan manusia Indonesia yang taat dan taat kepada pemimpin, seperti gotong royong, menjaga stabilitas, dan perkembangan manusia. Nilai-nilai karakter tersebut sengaja ditonjolkan karena hanya mereka yang memiliki karakter tersebut yang dapat menjadi penguasa yang dapat mempertahankan status serta mendukung keberhasilan program pembangunan.

Di sisi lain, nilai-nilai karakter seperti kritis, jujur, sisi kebenaran dan keterbukaan, dan keberanian membela kaum tertindas, hampir tidak mendapat tempat dalam kurikulum pendidikan, karena nilai-nilai karakter tidak hanya dapat mengancam stabilitas nasional yang diperlukan untuk pembangunan tetapi juga mereka dapat merusak otoritas kekuasaan pemerintah ${ }^{7}$.

Proses pelaksanaan pendidikan karakter religius atau bisa disebut karakter islami, banyak sekali langkah atau strategi yang digunakan di lembaha RA Al Wafa seperti halnya melakukan perbuatan yang baik dan sopan. Setiap hari peserta didik diajarkan bagaiman dan seperti apa tingkah laku yang baik dan benar. Seperti halnya memberikan salam sebeum berangkat ke sekolah, mencium tangan kedua orang tua, memberikan salam terhadap guru ketika disekolah serta memberikan salam terhadap guru. Hal demikian sangat perlu ditanamkan kepada anak mulai sedini mungkin. Strategi pembelajaran memiliki keunikan-keunikan tersendiri. Sehingga tidak ada strategi pembelajaran tertentu yang dapat menjatuhkan strategi pembelajaran yang lain. Maka dari itu, seorang pendidik harus mampu memilih dan menentukan strategi

7 Djaswidi Al Hamdani, “THE CHARACTER EDUCATION IN ISLAMIC EDUCATION VIEWPOINT," Jurnal Pendidikan Islam UIN Sunan Gunung Djati 1, no. 02 (2014): 88-109.

Al-Manar : Jurnal Komunikasi dan Pendidikan Islam - Volume 10, Nomor 2, Desember 2021 
yang cocok dengan keadaannya. Ada beberapa prinsip yang harus diperhatikan dalam penggunaan strategi pembelajaran diantaranya: Berorientasi pada tujuan, Aktivitas, Individualitas dan Integritas. Beberapa prinsip tersebut sejalan dengan peraturan pemerintah No. 31 tahun $2013^{8}$.

Pembelajaran yang dilakukan di RA Al Wafa tidak semata-mata memberikan pelajaran seadanya, namun memakai kurikulum untuk memberikan arahan dalam proses pembelajaran yang dilakukan. Kurikulum dapat dijadikan pegangan bagi pendidik dalam melakukan proses belajar mengajar. Kurikulum juga dapat diartikan seperti alat bantu agar apa yang diharapkan bisa dicapai siswa dengan melakukan proses yang telah disediakan oleh kurikulum. Adapun fungs lain dari kurikulum dalam sebuah pendidika adalah sebagai alat untuk mencapai sebuah prestasi dan tujuan pendidikan.

Pendidikan karakter yang diterapkan dalam lembaga RA Al Wafa, yang sangat diprioritaskan adalah pendidikan akhlaq atau tingkah laku yang baik. Mengajarkan bagaimana bagaimana seorang anak harus patuh terhadap perintah kedua orang tuanya, berperilaku yang santun terhadap orang lain, bagaimana cara berperilaku terhadap teman. Pusat peneliti dan pengembangan badan kurikulum menerbitkan suatu pedoman pelaksanaan pendidikan karakter. Kementrian Pendidikan Nasional juga sudah melakukan penelitian dalam nilai-nilai pendidikan yang digunakan oleh pendidik untuk membentuk karakter anak bangsa yang mana hasil dari penelitiannya diperoleh dari berbagai macam agama, suku budaya dan pancasila dengan menempuh satu tujuan yaitu pendidikan nasional. Taat dan patuh terhadap ajaran agama mereka masing-masing adalah salah satu nilai agama yang harus di tanamkan sejak dini ${ }^{9}$.

Isu tentang pentingnya pendidikan karakter telah ramai diperbincangkan dibahas kembali bersamaan dengan meningkatnya kepedulian masyarakat Indonesia terhadap intoleran, kekerasan, teror, korupsi, dan perilaku dan sikap destruktif lainnya. Prioritas pembangunan nasional dalam Rencana Pembangunan Jangka Panjang Nasional (RPJP) (UU No. 17 Tahun 2007) tahun 2005-2025 meliputi terciptanya masyarakat yang berbudi pekerti, moral, etika, budaya, dan peradaban berdasarkan Pancasila. Ketika ada dukungan dan dorongan dari lingkungan, secara otomatis kekuatan karakter akan muncul. Peran keluarga, sekolah dan masyarakat juga sangat penting untuk menjaga dan memperkuat karakter seorang anak ${ }^{10}$.

Program atau acara aktivitas religius pada sekolah wajib dilaksanakan secara rutin dan berkesinambungan. Sebagai upaya penguatan pendidikan karakter siswa

8 (Gustinwati 2020)

9 Mulyono, "Menegaskan Karakter Pendidikan Nonformal."

10 Imam Gunawan, "PENDIDIKAN KARAKTER," 15/12/2015, 2012, 18, http://fip.um.ac.id/wpcontent/uploads/2015/12/15.1_Pendidikan-Karakter.pdf.

Al-Manar : Jurnal Komunikasi dan Pendidikan Islam - Volume 10, Nomor 2, Desember 2021 
dimasa kini ${ }^{11}$. Begitu pula dengan pendidikan keislaman. Pendidikan yang berbasis keislaman seperti sholat, puasa, shadaqah dan lainnya, juga perlu dibiasakan terhadap anak didik agar bisa menjadi umat yang beraqidah dan beriman serta memiliki ketekunan dalam beribadah terhadap tuhannya.

Dengan adanya penanaman karakter religius, maka terdapat pula penanaman keimanan dan keyakina terhadap tuhan. Dalam fase ini, pendidik khususnya di RA Al Wafa, memberikan pembelajaran keislaman yang berhubungan dengan ketuhanan, seperti sholat, puasa, zakat dan membaca al quran. Seseorang yang menanamkan karakter islam pada dirinya akan memberi ketertarikan pada orang-orang di sekitarnya untuk ikut menanamkan karakter islami. Cara berfikir, berperilaku, berbicara, berpakaian serta semua tingkah laku yang berhubungan dengan tuhan atau sesama manusia, akan menggunakan karakter atau mengikuti aturan-aturan agama yang dianutnya ${ }^{12}$. Yang paling penting dalam pendidikan keislaman adaalah pendidikan tauhid. Pendidikan tauhid ini merupakan pendidikan tentang hubungan manusai yang bisa di sebuh makhluq dengan Tuhan yang bisa disebut Khaliq. Hubungan makhluq dangan khaliq harus betul-betul dibina dan di perhatikan, karena hubungan antara makhluq dengan khaliq sangat penting.

Penerapan yang dilakukan di RA Al Wafa dalam memberikan pembelajaran keislaman melalui peraktek yang meliputi peserta didik secara langsung, seperti yang dikatakan salah satu guru yang mengajar di RA Al Wafa, setiap hari jum'at, peserta didik diajarkan bagaimana tata cara sholat yang benar, diajarkan menulis ayat-ayat alqur'an dan diajarkan bagaimana berpenampilan baik dan sopan. Pola pendidikan Rasulallah dalam menyampaikan pendidikan tradisi islam kepada kaum jahiliyah merupakan prestasi yang tinggi dalam bidang pendidikan yang ada dimuka bumi ini dan tidak akan pernah ada yang bisa menyamai terhadap pola pendidikan Rasulallah. Seperti yang disampaikan oleh Sofyan Sauri bahwasannya banyak dari kalangan sahabat yang menjadikan masyarakat yang berkarakter sehingga mereka rindu akan ajaran-ajaran yang pernah Rasulallah ajarkan pada masa itu. Sehingga dengan karakter yang ditanamkan atau diajarkan Rasulallah mereka semangat dan tidak pernah takut dalam berjihad untuk membeka agama Allah dan ikut serta dalam mensyiarkan ajaran-ajaran yang pernah diajarkan oleh Rasulallah. Dalam Al Quran dan Hadist telah dijelaskan tentang pendidikan anak usia dini (AUD) yang sesuai dengan ajaran agama islam ${ }^{13}$.

11 E. W Suryanti and F. D Widayanti, "Penguatan Pendidikan Karakter Berbasis Religius," Conference on Innovation and Application of Science and Technology (CIASTECH 2018), no. September (2018): 254-62.

12 dan Makhfu Kusno, Joko Purwanto, "MODEL PENDIDIKAN KARAKTER RELIGIUS BERBASIS PADA PENGETAHUAN MATEMATIKA SEKOLAH," Jurnalnasional.Ump.Ac.Id, 2014, 1-11.

${ }^{13}$ F Kh Elfan Fanhas and Mukhlis Gina Nurazizah, "Pendidikan Karakter Untuk Anak Usia Dini Menurut Q.S. Lukman : 13 - 19," PEDAGOGI: Jurnal Anak Usia Dini Dan Pendidikan Anak Usia Dini Volume 3, no. 3a (2017): 42-51, http://103.114.35.30/index.php/Pedagogi/article/view/1032.

Al-Manar : Jurnal Komunikasi dan Pendidikan Islam - Volume 10, Nomor 2, Desember 2021 
Amanah dari Allah yang patut kita lindungi adalah seorang anak. Mendidik dan membimbingnya adalah kewajiban orang tuanya sehingga bisa menjadi sosok manusia yang bisa memberikan kebanggaan tersendiri pada orang tuanya serta bisa berguna bagi bangsa dan negara ini ${ }^{14}$. Pendidikan anak mulai usia dini akan memberikan hasil yang maksimal dan mudah bagi pendidik untuk memberikan pembelajaran. Seperti yang disampaikan oleh salah satu guru yang mengajar di lembaga RA Al Wafa, Lailatul Ikrimah, ada beberapa kemudahan dan kesulitan yang dialami ketika mengajar anak didiknya yang masih diusia dini. Menurutnya (Lailatul Ikrimah), "Lebih mudah mengajar anak TK dari pada yang sudah remaja, kan anak kecil lebih mudah dibentuk. Seperti halnya kertas putih yang kosong, nah, bagaimana kita mau menulisnya”.

Dalam artian, mengajar anak RA atau TK lebih mudah dibandingkan mengajar anak yang usianya sudah memasuki masa-masa remaja, karena anak kecil (usia dini) lebih mudah dibentuk karakternya atau pun suatu hal yang lain dibandingkan dengan mereka yang sudah memasuki masa-masa remaja seperti penuturanya dalam sebuah kiasan anak kecil bagaikan selembar kertas putih yang kosong yang mana kita bebas mau menulis ataupun melukis sesuatu diatasnya dengan leluasa.

Sedangkan kendala atau kesulitan dalam mengajar atau mendidik anak usia dini seperti yang disampaikan oleh lailatul ikrimah "kita harus telaten pak, apalagi menghadapi anak yang IQ nya dibawah standart atau dibawah rata-rata". Dalam artian yang dapat kami simpulkan dari penuturan diatas, ke telatenan, kesabaran dan keikhlasan dalam mendidik anak usia dini harus ditanamkan pada jati diri seorang guru atau pendidik. Karena tidak semua anak didiknya memiliki pemikiran yang sama, tidak memiliki IQ yang sama, diantaranya pasti ada perbedaan yang bermacammacam. Namun, ketika seorang pendidik bisa menanamkan kesabaran dan keikhlasan dalam jati dirinya, pasti akan lebih mudah untuk menyampaikan atau memberikan pendidikan pada anak didiknya

Pembangunan atau pendidikan karakter lebih idealnya dimulai semenjak usia dini agar seorang anak lebih cepat menanggapi dan menerima pembelajaran yang diberikan oleh guru atau pendidik seperti yang dikatakan oleh Lailatul Ikrimah salah satu pengajar di RA Al Wafa tempat yang kami buat penelitian, "anak kecil ibaratkan kertas kosong", jadi kita lebih leluasa menulis dalam kertas tersebut. Begitu juga dengan pendidikan, jika pendidikan dilakukan atau diberikan kepada anak mulai dari kecil, maka seorang anak lebih cepat tanggap dan lebih mudah dibentuk karakternya sehingga bisa memberikan hasil yang lebih maksimal.

14 Rasid Rasid, Zainal Abidin, and Pahendra Pahendra, "Pendidikan Non-Formal: Peranan Keluarga Dalam Pembinaan Anak," Jurnal Ilmu Manajemen Sosial Humaniora (JIMSH) 3, no. 1 (2021): 10-23, doi:10.51454/jimsh.v3i1.53. 
Pendidikan yang bagus dimulai ketika kehidupan ditahun pertama. Karena pada waktu itu banyak potensi pada diri manusia yang berkembang secara pesat ${ }^{15}$. Pada usia tersebut banyak dikalangan pendidikan yang menyebutnya dengan usia emas. Usia emas ini berlangsung saat bayi masih dalam kandungan sampa usia 6 tahun (0-6 Tahun) 16.

Namun, perlu diketahui, anak pada usia dini, memiliki karakter yang berbedabeda begitu juga dengan proses pertumbuhannya. Sangat berbeda dengan pertumbuhan anak yang sudah beranjak dewasa. Maka dari itu, seorang pendidik harus bisa mengetahui berbagai macam karakter dasar seorang anak pada usia dini ${ }^{17}$. Pertumbuhan seorang anak sangat pesat pada masa usia emas tersebut, maka dari itu, orang tua, pengajar atau keluarga harus sering memberikan stimulus atau rangsangan yang baik bagi anak, karena sejatinya seorang anak adalah peniru yang sangat handal terhadap apa yang dilakukan oleh orang-orang disekitarnya. Maka demikin, berikanlah contoh karakter yang baik terhadap anak sehingga mereka bisa meniru dan mencontoh apa yang dilakukan oleh orang disekitarnya ${ }^{18}$.

Dalam dua dekade terakhir ini, terminologi lebih umum digunakan untuk memberikan gambaran investigasi masalah etika dilingkungan sekolah. Pembelajaran tentang nilai-nilai etika dalam pendidikan karakter lebih memungkinkan untuk bisa memilih dan memilah mana yang benar dan mana yang salah. Sedangkan pelaksanan dalam lingkungan masyarakat kurang mendapatkan perhatian. Akibatnya, pendidikan karakter kurang menyentuh terhadap tindakan dan perilaku peserta didik ${ }^{19}$. Nilai adalah sifat-sifat yang berperan penting pada kehidupan manusia 20.

Lain halnya seperti di pondok pesantren. Sebagai lembaga pendidikan, pesantren memiliki ciri khas tersendiri. Pesantren memiliki tradisi dan strategi dalam bidang keilmuan yang berbeda dengan lembaga-lembaga lainnya. Meskipun apa yang diajarkan sama tapi strateginya sangat berbeda. Begitu juga penerapan pola hidup bermasyarakat, pesantren memiliki cara tersendiri sehingga menjadikan karakter tersendiri bagi pondok pesantren 21. Di pondok pesantren darul akhlaq tempat

15 Loeziana Uce, "THE GOLDEN AGE: MASA EFEKTIF MERANCANG KUALITAS ANAK," International Journal 64, no. 1 (2008): 205-21, doi:10.1177/002070200906400118.

16 Indrawati, "Pendidikan Anak Usia Dini Pada Masa Golden Age," Al-Ashlah: Journal of Islamic Studies 1, no. 1 (2020): 1-19.

17 La Hadisi, "Pendidikan Karakter Pada Anak Usia Dini La Hadisi," Jurnal Al-Ta'did 8, no. 2 (2015): 50-69, http://repository.iiq.ac.id/handle/123456789/228.

18 Hafizhatul Munawwarah, "Pendidikan Karakter Anak Perspektif Aliran Filsafat Behaviorisme," Jurnal Golden Age 5, no. 02 (2021): 71-82.

19 Djaswidi Al Hamdani, "THE CHARACTER EDUCATION IN ISLAMIC EDUCATION VIEWPOINT."

20 Abdul wahab Hisbullah, "IMPLEMENTASI PENANAMAN NILAI-NILAI MORAL DAN KEMANDIRIAN SOSIAL DI SEKOLAH DASAR PLUS QURROTA A'YUN KOTA MALANG,” Paper Knowledge . Toward a Media History of Documents, no. 15761001 (2014).

21 Adib Rifqi Setiawan and Whasfi Velasufah, "Nilai Pesantren Sebagai Dasar Pendidikan Karakter," PELANTAN, no. September (2019): 1-8, doi:10.31237/osf.io/hq6kz.

Al-Manar : Jurnal Komunikasi dan Pendidikan Islam - Volume 10, Nomor 2, Desember 2021 
dimana RA Al Wafa berada, ada banyak kegiatan yang dilakukan mulai pagi sampai malam. Mulai dari sholat tahajjud, membaca al quran dan belajar. Pelajaran di pondok pesantren darul akhlaq ada dua macam yaitu pendidikan formal dan pendidikan non formal. Pendidikan formal meliputi RA, SMP dan SMA. Sedangkan pendidikan non formalnya yaitu sekolah madrasah diniyah.

Ada beberapa ilmuan muslim yang mengembangkan konsep-konsep karakter islam diantaranya Al Imam Ghazali dan Ibnu Miskawih. Yang mana pemikiranpemikiran mereka dalam mengembangkan konsep karakter islam tidak lepas dari ajaran-ajaran islam yang berasal dari Al Quran dan Hadist 22. Untuk mendapatkan pendidikan karakter yang bagus dan berlandaskan nilai-nilai keagamaan, maka butuh tindak lanjut yang tiada akhir terhadap proses pendidikan karakter ${ }^{23}$.

\section{KESIMPULAN}

Bagian kesimpulan harus disertakan dan harus menunjukkan dengan jelas keuntungan, batasan, dan kemungkinan penerapan isi teks naskah. Meskipun kesimpulan dapat meninjau poin utama naskah, jangan mereplikasi abstrak sebagai kesimpulan. Kesimpulan menguraikan tentang pentingnya naskah jurnal atau menyarankan aplikasi dan perluasan.

Berdasarkan penelitian di RA Al Wafa, pendidikan karakter menjadi salah satu pendidikan yang diutamakan. Hal ini tidak diragukan lagi, melihat dari induk lembaga RA Al Wafa, Yayasan Pondok Pesantren Darul Akhlaq, lembaga yang dipimpin langsung oleh salah satu keturunan Rasulallah, pendidikan karakter atau bisa disebut pendidikan akhlaq, akan sangat diperhatikan terhadap setiap siswa yang ada dibawah naungannya. Sehingga tidak diragukan lagi tentang pendidikan akhlaqnya.

Dari beberapa penjelasan di atas, sangat penting pendidikan karakter ditanamkan terhadap anak didik mulai usia dini. Karena pendidikan karakter akan digunakan dalam setiap kehidupan manusia. Pendidikan mulai sejak dini sangat memberikan pengaruh terhadap pola pikir seorang anak, karena masa-masa tersebut merupakan masa dimana seorang anak lebih peka pemikirannya dibandingkan dengan usia setelanya. Utamanya dalam segi peraktek, anak usia dini lebih cepat menerima pembelajaran dengan strategi praktek dibandingkan dengan pembelajaran yang seperti biasa dilakukan didalam kelas, seperti menulis dan membaca. Anak pada usia dini adalah seorang peniru yang sangat handal, karena setiap apa yang dilakukan oleh mereka yang ada disekitarnya, akan direkam dan disimpan dalam memori otaknya.

22 Tobroni, Nur Chanifah, and Saiful Akhyar Lubis, "Religious Character Teaching and Learning Model to Prevent Radicalism in Universities," Systematic Reviews in Pharmacy 11, no. 11 (2020): 10211, doi:10.31838/srp.2020.11.16.

23 La Hadisi, "Pendidikan Karakter Pada Anak Usia Dini La Hadisi." 
Pendidikan yang berhubungan dengan tuhan perlu dijadikan prioritas utama dalam kehidapan manusia, sehingga bisa menjadi manusia dengan karakter yang baik dan bertauhid yang kuat. Hal ini sangat tepat ketika diajarkan kepada anak mulai usai dini. Seperti sholat, seorang anak harus betul-betul dibimbing dan dibina, karena sholat merupakan ibadah yang paling utama dalam kehidupan manusia. Selain itu, pendidikan karakter yang berhubungan dengan sesama manusia juga harus diperhatikan.

\section{DAFTAR PUSTAKA}

Anitah, W sri. "Strategi Pembelajaran Tarannum." Repository.Ut.Ac.Id, 2007, 15-75.

Djaswidi Al Hamdani. "THE CHARACTER EDUCATION IN ISLAMIC EDUCATION VIEWPOINT." Jurnal Pendidikan Islam UIN Sunan Gunung Djati 1, no. 02 (2014): 88-109.

Dr. Wahidmurni, M.Pd. "PEMAPARAN METODE PENELITIAN KUALITATIF." Reserach Repository 549, no. 1 (2017): 40-42.

Elfan Fanhas, F Kh, and Mukhlis Gina Nurazizah. "Pendidikan Karakter Untuk Anak Usia Dini Menurut Q.S. Lukman : 13 - 19.” PEDAGOGI: Jurnal Anak Usia Dini Dan Pendidikan Anak Usia Dini Volume 3, no. 3a (2017): 42-51. http://103.114.35.30/index.php/Pedagogi/article/view/1032.

Gunawan, Imam. "PENDIDIKAN KARAKTER.” 15/12/2015, 2012, 18. http://fip.um.ac.id/wp-content/uploads/2015/12/15.1_PendidikanKarakter.pdf.

GUSTINWATI, SELVIA. Strategi Pembelajaran, 2020. doi:10.35542/osf.io/cr96u.

Hadisi, La. "Pendidikan Karakter Pada Anak Usia Dini La Hadisi." Jurnal Al-Ta'did 8, no. 2 (2015): 50-69. http://repository.iiq.ac.id/handle/123456789/228.

Hisbullah, Abdul wahab. "IMPLEMENTASI PENANAMAN NILAI-NILAI MORAL DAN KEMANDIRIAN SOSIAL DI SEKOLAH DASAR PLUS QURROTA A'YUN KOTA MALANG." Paper Knowledge . Toward a Media History of Documents, no. 15761001 (2014).

Indrawati. "Pendidikan Anak Usia Dini Pada Masa Golden Age." Al-Ashlah: Journal of Islamic Studies 1, no. 1 (2020): 1-19.

Kusno, Joko Purwanto, dan Makhfu. "MODEL PENDIDIKAN KARAKTER RELIGIUS BERBASIS PADA PENGETAHUAN MATEMATIKA SEKOLAH." Jurnalnasional.Ump.Ac.Id, 2014, 1-11.

Mufatihatut Taubah. "PENDIDIKAN ANAK DALAM KELUARGA PERSPEKTIF ISLAM Mufatihatut Taubah (Dosen STAIN Kudus Prodi PAI)." JUrnal Pendidikan Agama $\begin{array}{lllll}\text { Islam } & 3, & \text { no. } & 1 & \text { (2016): }\end{array}$ http://jurnalpai.uinsby.ac.id/index.php/jurnalpai/article/view/41.

Mulyono, Dinno (STKIP Siliwangi Bandung). "Menegaskan Karakter Pendidikan Nonformal." Jurnal Ilmiah Program Studi Pendidikan Luar Sekolah STKIP Siliwangi Bandung 1, no. 1 (2012): 63-68. http://e- 
journal.stkipsiliwangi.ac.id/index.php/empowerment/article/view/365.

Munawwarah, Hafizhatul. "Pendidikan Karakter Anak Perspektif Aliran Filsafat Behaviorisme." Jurnal Golden Age 5, no. 02 (2021): 71-82.

Nurratri Kurnia Sari, Linda Dian Puspita. "IMPLEMENTASI PENDIDIKAN KARAKTER DI SEKOLAH DASAR." Jurnal DIKDAS BANTARA 2 (2019): 57-72.

Prasetiya, Benny. Metode Pendidikan Karakter Religius Paling Efektif Di Sekolah. Lamongan: Academia Publication, 2021.

Prasetiya, Benny, Sofyan Rofi, and Bahar Agus Setiawan. "PENGUATAN NILAI KETAUHIDAN DALAM PRAKSIS PENDIDIKAN ISLAM." Journal of Islamic Education (JIE) III, no. 1 (2018): 1-15.

Rasid, Rasid, Zainal Abidin, and Pahendra Pahendra. "Pendidikan Non-Formal: Peranan Keluarga Dalam Pembinaan Anak." Jurnal Ilmu Manajemen Sosial Humaniora (JIMSH) 3, no. 1 (2021): 10-23. doi:10.51454/jimsh.v3i1.53.

Setiawan, Adib Rifqi, and Whasfi Velasufah. "Nilai Pesantren Sebagai Dasar Pendidikan Karakter." PELANTAN, no. September (2019): 1-8. doi:10.31237/osf.io/hq6kz.

Suryanti, E. W, and F. D Widayanti. "Penguatan Pendidikan Karakter Berbasis Religius." Conference on Innovation and Application of Science and Technology (CIASTECH 2018), no. September (2018): 254-62.

Tobroni, Nur Chanifah, and Saiful Akhyar Lubis. "Religious Character Teaching and Learning Model to Prevent Radicalism in Universities." Systematic Reviews in Pharmacy 11, no. 11 (2020): 102-11. doi:10.31838/srp.2020.11.16.

Uce, Loeziana. "THE GOLDEN AGE : MASA EFEKTIF MERANCANG KUALITAS ANAK." International Journal 64, no. 1 (2008): 205-21. doi:10.1177/002070200906400118. 